\title{
"Matrena", de Leopold Ritter Von Sacher-Masoch
}

\author{
Guilherme da Silva Braga
}

Leopold Ritter von Sacher-Masoch nasceu em 27 de janeiro de 1836 em Lemberg, cidade que na época situava-se na Galícia e hoje pertence à atual Ucrânia, embora sempre tenha se identificado com a cultura e a língua alemã.

Ao longo da vida dedicou-se ao estudo do direito, da matemática e da história, chegando a lecionar esta última disciplina na Universidade de Lemberg por algum tempo. Mais tarde, dedicado exclusivamente à carreira literária, tornou-se um autor popular e admirado por grandes escritores como Victor Hugo, Émile Zola e Henrik Ibsen.

A posteridade, contudo, relegou sua obra ao esquecimento quase total, à exceção do romance $A$ Vênus das peles. Neste livro, em parte autobiográfico, Masoch aborda em grande detalhe o tema do prazer erótico que se pode derivar do sofrimento físico - uma condição que viria a popularizar-se sob o nome com que foi descrita pelo psiquiatra Richard von Krafft-Ebing em seu tratado de perversões sexuais Psychopatia Sexualis: masoquismo.

Em 1895, com a sanidade abalada, Masoch foi declarado morto no dia 3 de março, em Lindheim. A data, no entanto, é controversa: há suspeitas de que o escritor tenha sido levado a um manicômio em Mannheim, onde teria vivido por outros dez anos. 
Guilherme da Silva Braga. "Matrena", de Leopold Ritter Von Sacher-Masoch

O conto "Matrena" foi publicado em Lola. Geschichten von Liebe und Tod (München: Heyne, 1985).

\section{Matrena}

Der Gutsherr Baraniewski - Gott habe ihn selig! - war ein gar hübscher und verwegener Mann, nur allzu kühn den Mädchen gegenüber. Er machte sich auch kein Gewissen daraus, dem Manne seine angetraute Frau zu nehmen, hatte überhaupt kein Gewissen. Dieser Baraniewski sah Matrena das allererste Mal auf dem Jahrmarkt. Wenn er ein Weib traf, von ferne nur, hob er die Nase wie ein Jagdhund, der ein Wild wittert. So war es auch hier, und er strich sich den Schnurrbart, und die Matrena sah ihn gleichfalls an. Warum sollte sie ihn nicht ansehen? Er war ein schöner Mann und gekleidet wie der Zarewitsch.

Sie hatte eine Art zu gehen, welche die Männer anzog. Sie drehte sich beim Gehen in den Hüften so, daß ihre langen Zöpfe ihren Nacken peitschten. Und der schöne Herr folgte ihr und flüsterte ihr allerhand Schönheiten zu.

Nicht lange darauf traf er sie beim Ziehbrunnen. War wohl kein Zufall, daß es so kam. Sie wurde rot, und weil sie nicht wußte, was sie reden sollte, so gab sie seinem Pferde zu trinken aus ihrer Kanne, und er stand dabei und sprach ihr von seiner Liebe. Erst schämte sich Matrena, als sie ihn aber so verliebt sah, da bekam sie Courage und lachte ihn aus. "Ihr seid ein Mann", sagte sie, "ich sollte Euch gar nicht anhören, denn ich habe einen Teuren, das ist Olex Kostka, mit dem mich mein Vater verlobt hat, aber es macht mir Spaß Euch so toll zu sehen."

Sie hatte Lippen wie Kirschen, die sah er und wollte sie gern küssen. "So und so", rief er, "als ich ein kleiner Junge war, habe ich mir das Obst am liebsten aus fremdem Garten geholt!" - “Und als ich ein kleines Mädchen war", gab sie zur Antwort, "da belustigte 
ich mich damit, dem Maikäfer einen Faden an das Bein zu binden, und lachte, wenn er zappelte und schwirrte und mir doch nicht entkommen konnte, und nun lache ich über Euch!" Und jedesmal, wenn er von seiner Liebe sprach, von den Qualen, die sie ihm bereitete, lachte sie nur und rief: "Flieg, Maikäfer, flieg!"

Und wieder einmal kam er, als sie beim Bache wusch und sich bückte, um die Wäsche zu spülen, und er sah ihre großen schönen Hüften, schlug sie drauf, daß es nur so klatschte, und lachte, sie aber war rot geworden und hieß ihn gehen.

Doch was half es ihr? Er ließ nicht ab, das war nicht der Mann, sich leicht abweisen zu lassen, wenn er einmal Passion hatte auf ein Weib.

Matrena schlug ihn einmal. - Wozu war das etwa gut? - Er kam doch - kam doch und drang zum Fenster herein, das sie offengelassen hatte, die Nachtigallen zu hören, die so schön in der Sommernacht sangen. Kam doch und küßte sie. Ergriff sie so im Hemd - sie hatte kaum Zeit, ihren kurzen Lammpelz überzuziehen. Es half ihr nichts, daß sie ihn wieder schlug und schrie. Er küßte sie doch. Nichts half ihr, alles wendete sich gegen sie, sie hat es später selbst erzählt, und mehr als einmal. Sie dunstete in ihrem Pelz und wurde noch heißer vom Ringen, die Schaffelle verbreiteten einen üblen Geruch. Er aber flüsterte: "Wie gut das riecht, und du erst... der Geruch eines gesunden Mädchenleibes berauscht mich!" Ist das nicht zum Lachen? Das Lammfell schien angewachsen an ihre vollen runden Glieder, und auch das gefiel ihm. "Ist es doch", rief er, "als kämpfe ich mit einem wilden, zottigen Tier!" Und er lachte, der Unmensch, obwohl er doch die Krallen und die Zähne dieses schönen Tieres fühlte.

Dann aber war sie es, die ihn zurückhalten wollte. Baraniewski, der stolze Herr, stieß sie weg, sie indes packte ihn noch einmal bei Haar und Bart. Er riß sich los, so daß Büschel seiner Haare in ihren Händen blieben, und schwang sich auf sein Pferd.

Matrena gab keinen Laut von sich. Rasch band sie ihr Haar zusammen, nahm einen derben Strick, machte eine Schlinge, führte 
Guilherme da Silva Braga. "Matrena", de Leopold Ritter Von Sacher-Masoch

das beste Pferd heraus aus dem Stall, sprang auf den Rücken desselben und folgte dem schönen, stolzen Herrn, der schon einen Vorsprung gewonnen hatte.

Die Brücke donnerte unter den Hufen seines Pferdes. Nun wußte sie, wie weit er war, denn die Nacht hatte ihn verschlungen, und sie sah nur seitwärts die leuchtenden Augen eines Wolfes, der sie musterte, und ein Stück faulen Holzes, das an dem Wege lag und leuchtete.

Da war ein Zaun, der ihm den Weg versperrte. Im Nu war er drüber, und ehe man zehn zählen konnte, war auch sie zur Stelle und sprang gleichfalls mit ihrem Kosakenpferd hinüber. Sprang ihm auch nach über den Graben, über den er gesetzt hatte, und schwamm ihm nach durch den Fluß, daß das Wasser nur so plätscherte und aufschäumte.

Fort ging es, immer fort. Jetzt mitten durch einen Hain, mitten durch die Bäume, daß die Äste ihnen ins Gesicht schlugen und sich an seine Kleider klammerten und ihr das Hemd vom Leibe rissen. Nun vorwärts durch das Maisfeld, daß die hohen Stämme nur so krachten, durch das Korn, durch den Weizen, was liegt daran? Durch die schlafende Schafherde, den Grabhügel hinauf, hinab. Da waren sie mitten in der Steppe, die um sie rauschte, ein Meer, ein stürmisches Meer, und nur der Himmel war über ihnen.

Baraniewski verlor wohl den Mut, er hörte das Knallen ihrer Peitsche näher und näher, hörte ihren Zuruf, mit dem sie das Pferd ermunterte, hörte das Schnauben des Tieres, fühlte seinen heißen Atem. Sein Pferd stürzte, Matrena jauchzte auf. Doch schon riß er es empor, und es ging weiter, wie auf der Hetzjagd hinter dem Fuchs her.

Wie pochte ihm das Herz, dem Verräter! Ja, hundert Arme schienen sich nach ihm auszustrecken, hundert Arme aller der Verratenen, Betrogenen, Verlassenen, Gemordeten. Weiße Arme, die aus dem dunklen Zobelpelz nach ihm langten, und braune Arme, die aus groben Hemden hervorkamen, und oben Jagten die Sterne ihm nach und weiße Gestalten in flatternden Gewändern, den toten 
Bräuten gleich, die um Mitternacht tanzen und ihre Tänzer erwürgen mit ihren weichen, duftigen Haaren.

Und wirklich, sie holt ihn ein. Sie wirft die Schlinge - einmal, ein zweites Mal -, da hat sie ihn, reißt ihn vom Pferde und macht halt und schöpft Atem.

Baraniewski sucht die Schlinge, die ihm den Hals zusammenschnürt, zu lockern, aber ein Ruck ihres starken Armes, und er liegt vor ihr und schnappt nach Luft, wie ein Fisch schnappt er, den man gefangen und auf den Sand hingeworfen hat, und fleht um sein Leben.

Matrena schüttelt nur den Kopf.

"Ich will dich zur Frau nehmen", beteuert er.

Sie lacht ihn nur aus.

"Dein Sklave will ich sein", beginnt er von neuem, sie aber schneidet ihm das Wort ab.

"Bete zu Gott. Du mußt sterben." - "Hast du kein Erbarmen mit mir?" - "Nein."

Dann treibt sie ihr Pferd an und ruft: "Maikäfer, flieg!" und lacht dabei, wie ein Teufel lacht sie. "Flieg, Maikäfer, flieg !"

Einige Zeit lief er neben ihrem Pferde her, dann blieb er zurück, fiel zur Erde, und nun schleifte sie ihn hinter sich, bis er zu ihren Füßen verendete. Noch war er nicht ganz tot, als schon die Raben um ihn kreisten und sich auf ihn stürzten.

"Nur zu!" rief ihnen Matrena zu, "hackt ihm die Augen aus, meine Freunde, reißt ihm das Fleisch stückweise vom Leibe - das schmeckt, so frisch und lebendig, nicht wahr? Oh, könnt ich dich nur selbst zerreißen mit meinen Zähnen!"

So endete Baraniewski, der schöne, stolze Herr, und Matrena hielt Hochzeit mit Olex Kostka.

Wie es möglich ist, daß er sie trotzdem genommen hat? Warum nicht? Hat sie nicht selbst ihre Ehre gerächt? Konnte ihr jemand einen Vorwurf machen? 
Guilherme da Silva Braga. "Matrena", de Leopold Ritter Von Sacher-Masoch

\section{Matrena}

Gutsherr Baraniewski - Que Deus o tenha! - era um homem deveras elegante e ousado, mas muito atrevido para com as moças. Ele não tinha escrúpulo algum quanto a roubar a esposa legítima de um outro homem; absolutamente escrúpulo algum. Baraniewski avistou Matrena pela primeira vez na feira. Quando ele via uma mulher, ainda ao longe, levantava o nariz como um cão de caça que fareja a presa. Foi o quanto se passou também nesta ocasião: Baraniewski cofiou o bigode e Matrena olhou-o com indiferença. Por que não haveria de olhá-lo? Ele era um homem bonito e estava vestido como o tsarévitche.

Ela tinha um jeito de andar que encantava os homens. Com o balanço dos quadris, suas longas tranças batiam-lhe na nuca como açoites. O belo nobre pôs-se em seu encalço e começou a cochicharlhe toda sorte de galanterias.

Pouco tempo depois, os dois encontraram-se junto ao poço. Essas coisas não acontecem por acaso. A garota enrubesceu e, como não soubesse o que falar, logo deu de beber a seu cavalo, enquanto o nobre ficou a seu lado falando sobre o amor que lhe tinha. No início Matrena sentiu vergonha, mas ao vê-lo tão enamorado ela riu. "O senhor é um homem", disse ela. "Eu não devia lhe dar ouvidos, pois tenho meu noivo, Olex Kostka, a quem meu pai me prometeu. Mas gosto de ver o senhor assim fogoso."

Seus lábios eram como cerejas que Baraniewski ansiava por beijar. "Bem", começou ele, "quando menino eu sempre gostava mais das frutas colhidas no pomar alheio!" - "E quando eu era menina", retrucou ela, "eu me divertia amarrando um fio de linha na pata dos besouros e ria enquanto eles se debatiam e zumbiam sem conseguir escapar e, agora, rio do senhor!" E sempre que ele falava de amor e do quanto sofria por ela, Matrena dava uma risada e dizia: "Voa, besourinho, voa!" 
E mais uma vez ele apareceu quando ela estava lavando roupa no córrego, abaixada para enxaguar uma peça: viu aqueles quadris grandes e atraentes, deu-lhes um sonoro tapa e riu, enquanto ela enrubesceu e mandou-o embora.

Mas de que adiantou? Baraniewski não desistiu: era o tipo de homem que não aceita recusas quando se inflama por uma mulher.

Matrena deu-lhe um tapa. - Mas para quê? - Ele insistiu insistiu e entrou pela janela, que ela havia deixado aberta para ouvir os rouxinóis cantarem lindas canções na noite de verão. Insistiu e começou a beijá-la. Agarrou-a pela camisola - Matrena mal teve tempo de cobrir-se com um casaquinho curto de pele de cordeiro. Nem mesmo os tapas e os gritos adiantavam. O nobre não parava com os beijos. Nada adiantava: tudo se voltava contra ela, como a própria Matrena viria a contar depois, em mais de uma ocasião. Ela começou a suar nas peles e a sentir calor naquele embate; o tosão exalava um odor pungente. Ele, no entanto, sussurrou: "Que cheiro bom, e na primeira... ah, esse cheiro de mulher me deixa louco!" Não é ridículo? $\mathrm{O}$ casaco de pele parecia estar grudado àqueles braços exuberantes, o que também o agradava. "Parece que eu estou lutando com um bicho peludo e selvagem!" E o desgraçado ria, mesmo sentindo as unhas e os dentes daquele lindo animal.

Mas logo era ela que não queria largá-lo. Baraniewski, o distinto nobre, empurrou-a para longe, porém Matrena voltou a agarrar-lhe as barbas e o cabelo. Ele conseguiu se soltar, mesmo que à custa de alguns tufos de cabelo, e logo montou em seu cavalo.

Matrena não fez um ruído sequer. Às pressas, prendeu o cabelo, pegou uma corda grossa, fez um laço, tirou o melhor cavalo do estábulo, saltou-lhe às costas e seguiu o belo e distinto nobre, que já ganhara uma boa vantagem.

A ponte estrondeou sob os cascos do cavalo. Só assim Matrena soube onde ele estava, pois a noite o encobria, e nesse instante ela percebeu, de soslaio, o olhar brilhante de um lobo que a espreitava e um pedaço de madeira podre que cintilava no meio do caminho. 
Guilherme da Silva Braga. "Matrena", de Leopold Ritter Von Sacher-Masoch

Na estrada, uma cerca bloqueava o caminho de Baraniewski. No instante seguinte ele a havia pulado, e antes que alguém pudesse contar até dez Matrena também a saltava com sua montaria. Ela também o seguiu pelo cemitério, onde ele se embrenhara, e nadou em seu encalço no rio, onde a água chapinhava e espumava.

A perseguição parecia não ter fim. Logo ela corria atrás dele pelo bosque, em meio às árvores, com os galhos batendo-lhes no rosto, enganchando-se nas roupas dele e arrancando a camisola que cobria o corpo dela. Em seguida os dois cruzaram o milharal, onde as espigas estalavam, depois os campos de trigo - mas para quê? Então passaram por um rebanho de ovelhas adormecidas, subindo e descendo a colina. Por fim chegaram à estepe sussurrante, com o mar, o mar revolto, e nada mais além do céu ao redor.

Baraniewski perdeu a coragem; ele ouviu os estalos do chicote cada vez mais perto, os brados com que ela incitava o cavalo, os relinchos do animal, sentiu aquela respiração quente. Seu cavalo caiu, e com isso Matrena rejubilou-se. Mas logo o nobre o pôs mais uma vez de pé e seguiu adiante, como estivesse em plena caça à raposa.

Como palpitava aquele coração tirânico! Ah, era como se uma centena de braços se estendessem na direção dele, os braços de todas as que sofreram com a traição, com a trapaça, com o abandono e o assassinato. Braços pálidos em casacos de zibelina tentavam agarrálo, braços morenos em camisolas rústicas surgiam-lhe às costas e, lá do alto, as estrelas perseguiam-no junto com figuras lívidas envoltas em mantos diáfanos, como as noivas mortas que à meia-noite dançam e enforcam seus parceiros com os cabelos brancos e perfumados.

Então Matrena o alcançou. Ela atira o laço - uma, duas vezes e então acerta o alvo, derruba-o do cavalo, para e toma fôlego.

Baraniewski tenta afrouxar o nó que lhe aperta o pescoço, mas com um puxão vigoroso ele se debate aos pés dela, arquejando como um peixe que, depois de fisgado, é atirado na areia e implora para que o deixem viver. 
Matrena balança a cabeça.

“Eu quero casar com você", ele exclama.

Ela apenas ri.

"Quero ser seu escravo", ele tenta prosseguir, mas logo é interrompido.

"Faça suas preces. Você vai morrer." - "Tenha piedade de mim!" - “Não."

Nesse momento ela incita o cavalo e grita: "Voa, besourinho!" e solta uma risada como a de um demônio. "Voa, besourinho, voa!"

Por algum tempo Baraniewski corre ao lado do cavalo, mas logo fica para trás e cai por terra enquanto Matrena o arrasta, até que ele expira a seus pés. Antes do último suspiro os corvos já o rodeavam e investiam sobre ele.

“Vamos, meus amigos!", gritou Matrena. "Arranquem os olhos, despedacem a carne - deve estar muito saborosa assim, tão fresca e tão viva, não é mesmo? Ah, se eu também pudesse destroçar você com os meus dentes!"

E assim acabou Baraniewski, o belo e distinto nobre, e Matrena celebrou suas núpcias com Olex Kostka.

Como é possível que ele a tenha aceito depois de tudo o que aconteceu? Mas por que não? Afinal, ela mesma não vingou sua honra? Será que alguém poderia fazer-lhe alguma censura? 